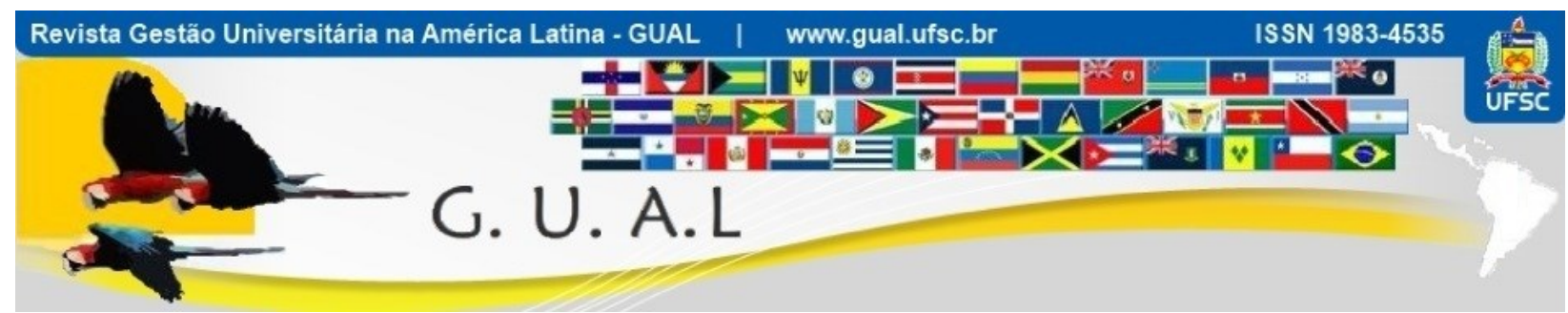

DOI: http://dx.doi.org/10.5007/1983-4535.2015v8n1p68

\title{
COMPARTILHAMENTO DE CONHECIMENTO: OS MEIOS UTILIZADOS NO CONTEXTO DA EDUCAÇÃO A DISTÂNCIA
}

\section{KNOWLEDGE SHARING: THE MEANS USED IN THE CONTEXT OF DISTANCE EDUCATION}

Carolina Schmitt Nunes, Doutoranda Universidade Federal de Santa Catarina - UFSC nunes.carolinas@gmail.com

Maurício Rissi, Doutor Universidade Federal de Santa Catarina - UFSC mauricio.rissi@ufsc.br

Marina Keiko Nakayama, Doutora Universidade Federal de Santa Catarina - UFSC marina@egc.ufsc.br

Andressa Sasaki Vasques Pacheco, Doutora Universidade Federal de Santa Catarina - UFSC andressa.ufsc@gmail.com

ESTA PESQUISA RECEBEU APOIO DA FAPESC.

Recebido em 12/janeiro/2014

Aprovado em 11/novembro/2014

Sistema de Avaliação: Double Blind Review

Esta obra está sob uma Licença Creative Commons Atribuição-Uso. 


\title{
RESUMO
}

O objetivo do artigo é identificar e analisar os meios pelos quais os integrantes de um curso de graduação na modalidade a distância utilizam para compartilhar conhecimento. A pesquisa foi realizada com agentes do curso de graduação a distância em Administração na Universidade Federal de Santa Catarina. Foram realizadas 29 entrevistas com participantes de seis diferentes funções no curso. Como principais resultados, verificou-se que o compartilhamento de conhecimento ocorre de espontâamente e também formalmente. Usam-se diferentes meios para o compartilhamento, os mais recorrentes são: e-mail, site, blogs, chats e redes sociais como meios que fazem uso de tecnologias da informação. Observou-se também que os encontros presenciais são momentos de compartilhamento intenso e o polo de apoio presencial se caracteriza como um ambiente adequado para que esse processo ocorra.

Palavras-chave: Compartilhamento de Conhecimento. Educação a Distância. Meios de compartilhamento.

\begin{abstract}
The objective of this Article is to identify and analyze the means by which the members of a graduate course in the modality the distance use to share knowledge. The research was conducted with agents of the undergraduate course the distance in Administration at Universidade Federal de Santa Catarina. 29 interviews was conduct with participants from six different functions within the course. As one of the main results, it was found that the knowledge sharing occurs spontaneously and also formally. As to the means used were identified if the e-mail, website, blogs, and chats, and social networks as a means mediated by information technology and the-face meetings as opportunities for sharing intense. And the presential support pole characterized as a appropriate environment for this process occurred.
\end{abstract}

Keywords: Knowledge Sharing, Distance Education, Media sharing. 


\section{INTRODUÇÃO}

A educação a distância (EaD) é caracterizada, de acordo com Moore e Kearsley (2007), pela separação geográfica de professores e alunos durante todo ou a maior parte do tempo em que aprendem e ensinam, a transmissão de informações e as interações são estabelecidas, na maioria das vezes através de alguma tecnologia de informação e da comunicação (TIC).

A separação geográfica e muitas vezes temporal entre professores e alunos, característica marcante da modalidade a distância, pode dificultar a interação entre os agentes envolvidos no processo de ensino e aprendizagem. As interações são o caminho pelo qual os alunos transformam a informação que lhes foi passada em conhecimento com aproveitamento pessoal e valor (ANDERSON, 2003; CHAO; HWU; CHANG, 2011), além disso, é também por meio das interações que o compartilhamento de conhecimento ocorre (DAVENPORT; PRUSAK, 2003; HONG; SUH; KOO, 2011).

Conscientes do avanço tecnológico e da adoção por parte da modalidade a distância dessas novas ferramentas de comunicação bem como da especificidade da existência do Polo de Apoio Presencial no Sistema Universidade Aberta do Brasil (UAB), busca-se neste trabalho identificar e analisar os meios pelos quais os agentes de um curso de graduação na modalidade a distância participante do Sistema UAB utilizam para compartilhar conhecimento.

\section{FUNDAMENTOS TEÓRICOS}

$\mathrm{Na}$ tentativa de compreender as diferentes faces dessa problemática, buscou-se aporte teórico na área da Gestão do Conhecimento, a fim de identificar o que a literatura traz como formas de compartilhar conhecimento e também na área da Educação a Distância, onde o objetivo foi fazer um levantamento das ferramentas utilizadas para a comunicação e interação.

\subsection{COMPARTILHAMENTO DE CONHECIMENTO}

Entende-se por compartilhamento de conhecimento a transferência do conhecimento, seja essa espontânea (informal) ou estruturada (formal), entre os membros da organização (DAVENPORT, 1998), é o ato de tornar o conhecimento disponível para os outros indivíduos dentro da organização (HONG; SUH; KOO, 2011). O principal objetivo de compartilhar conhecimento é a criação de novos conhecimentos por meio da combinação de diferentes 


\section{COMPARTILHAMENTO DE CONHECIMENTO: OS MEIOS UTILIZADOS NO CONTEXTO DA \\ EDUCAÇÃO A DISTÂNCIA \\ DOI: http://dx.doi.org/10.5007/1983-4535.2015v8n1p68}

conhecimentos existentes, bem como a melhoria na exploração de conhecimentos existentes (CHRISTENSEN, 2007).

O compartilhamento de conhecimento é realizado em forma de fluxo de conhecimento, incluindo pelo menos dois participantes, um que oferece conhecimento e outra que o recebe, dessa forma o conhecimento deve ser comunicado e então o receptor deve percebê-lo e interpretá-lo (HENDRIKS, 1999). O fluxo de conhecimento em uma organização está centrado no desenvolvimento de canais ou redes de fornecedores e requerentes (SHIN; HOLDEN; SCHMIDT apud HONG; SUH; KOO, 2011), e é dirigido por processos de comunicação e fluxos de informação. Este processo ocorre entre os indivíduos e também contribui para a aprendizagem individual e organizacional (NIDUMOLU; SUBRAMANI; ALDIRCH, 2001 apud HONG; SUH; KOO, 2011).

As Tecnologias da Informação e da Comunicação - TICs têm um papel importante no suporte ao compartilhamento, principalmente do compartilhamento que envolve conhecimentos explícitos. No entanto a forma mais efetiva de compartilhar o conhecimento seja tácito (aquele que é subjetivo e difícil de ser codificado) ou explícito (aquele que é codificado e estruturado) - consiste em criar um ambiente adequado para compartilhar de forma sistemática o conhecimento (LEE; YANG, 2000).

Com relação a forma de compartilhar conhecimento, há uma diversidade das mesmas. Estas podem ser estruturadas ou espontâneas. A CEN (2004), considerada como métodos e ferramentas para o compartilhamento de conhecimento as intranets/portais, bases de dados, colaborações, comunidades de prática, rotação de pessoal, treinamentos, seminários e capacitações.

Balerini (apud SANTOS, 2010, p. 44), afirma que são meios as "conversas informais (cafézinho); trocas presenciais semi-estruturadas via brainstorming; meios presenciais estruturados, como palestras, conferências e treinamentos; trocas virtuais simples, como emails e trocas virtuais organizadas - educação a distância e videoconferência".

Já a Asian Productivity Organization - APO (2009) apresenta duas abordagens de compartilhamento de conhecimento, uma denominada "armazenagem" que está relacionada com as maneiras para deixar o conhecimento acessível para que outras pessoas possam utilizar, e a segunda, chamada de "fluxo" que refere-se a transferência direta de conhecimento entre as pessoas. 


\section{COMPARTILHAMENTO DE CONHECIMENTO: OS MEIOS UTILIZADOS NO CONTEXTO DA \\ EDUCAÇÃO A DISTÂNCIA \\ DOI: http://dx.doi.org/10.5007/1983-4535.2015v8n1p68}

$\mathrm{Na}$ tentativa de sistematizar os meios pelos quais o compartilhamento de conhecimento ocorre, Young (2010) reuniu em uma lista os métodos e técnicas praticados pelas organizações de maior sucesso no mundo em suas iniciativas de implementação de Gestão do Conhecimento. Esses métodos e técnicas foram publicados pela Asian Productivity Organization - APO. Os métodos e técnicas de GC que possibilitam compartilhamento de conhecimento são divididas em aquelas que fazem uso de tecnológicas da informação e aquelas que não fazem uso. O quadro a seguir apresenta as ferramentas e métodos de acordo com essa classificação.

\begin{tabular}{|l|l|}
\hline Métodos e Técnicas com o uso de TI & Métodos e Técnicas sem o uso de TI \\
\hline Biblioteca de documentos & Brainstorming \\
\hline Bases de conhecimento & Assistência entre colegas \\
\hline Blogs & Aprendizagem e captura das ideias \\
\hline Serviços de Redes Sociais & Revisão depois da ação \\
\hline Voips & Narrativas \\
\hline Clusters de conhecimento; & Comunidades de prática \\
\hline Localizador de especialistas; & Espaços Físicos de Colaboração \\
\hline Espaços de colaboração virtuais; & Café do Conhecimento \\
\hline Portal de Conhecimento; & Taxonomias \\
\hline Vídeo compartilhado; & Mestre/aprendiz \\
\hline
\end{tabular}

Quadro 01 Métodos e Técnicas de Compartilhamento de Conhecimento.

Fonte: Adaptado de Young (2010).

É possível perceber certa homogeneidade no pensamento dos autores citados no que se refere as formas de compartilhar conhecimento: todos consideram formas estruturadas e não estruturadas de compartilhamento bem como técnicas e ferramentas suportadas e não suportadas por tecnologias da informação.

A partir do exposto, apresenta-se um panorama do uso das tecnologias da comunicação e informação na Educação a distância.

\subsection{USO DAS TICS NA EAD}

No contexto da educação a distância, observa-se através das gerações tecnológicas da $\mathrm{EaD}$ que houve uma mudança no uso das tecnologias, com a incorporação de novas sem necessariamente o descarte das mais antigas. As TICs surgidas na década de 1960 e consolidada na década de 1990, colaboraram para a expansão da $\mathrm{EaD}$, no entanto o uso das TICs provocou mudanças não apenas no campo educacional, sua influência pode ser percebida no estilo de vida da sociedade nas últimas décadas (ROMANI; ROCHA, 2001). 


\section{COMPARTILHAMENTO DE CONHECIMENTO: OS MEIOS UTILIZADOS NO CONTEXTO DA \\ EDUCAÇÃO A DISTÂNCIA \\ DOI: http://dx.doi.org/10.5007/1983-4535.2015v8n1p68}

Os autores Moore e Kearsley (2007) destacam que as tecnologias tem exercido papel fundamental, uma vez que possibilitam a disseminação de informações e conhecimentos, oportunizando o aprendizado. As TICs são amplamente utilizadas na $\mathrm{EaD}$, em razão, principalmente, da possibilidade de expandir a interação entre professor e aluno (ROMANI; ROCHA, 2001). Nesse sentido Belloni (2009) destaca a necessidade de utilizar TICs capazes de sustentar e criar uma comunicação pessoal (embora não presencial) a fim de garantir a interação.

São tecnologias recorrentes na educação a distância e utilizadas no mundo todo conforme as características de cada região e população o meio impresso, áudio e vídeo e utilizadas. No entanto, observa-se que a partir do computador e da interface web, as possibilidade de interação a distância - simultânea ou diferida foram modificadas, colocando a disposição dos agentes de EaD, técnicas rápidas, seguras e eficientes (DIAS; LEITE, 2010).

A internet permite o compartilhamento de informações em tempo real, possibilitando o estabelecimento de cooperação e comunicação entre grupos de indivíduos. Além disso, a internet dispõe de mecanismos de comunicação síncronos (demandam que os interlocutores estejam conectados no mesmo momento temporal para que possa haver comunicação) e assíncronos (os momentos de envio e recepção de mensagens são em tempo diferentes) (SOARES, 2012). Ainda nesse sentido, antes do advento da internet, as tecnologias utilizadas na EaD permitiam a comunicação de "um-para-muitos" (rádio, TV) ou de "um-para-um" (ensino por correspondência). A partir da Internet, tem-se além das formar de comunicação citadas, a comunicação "muitos-para-muitos", ampliando expressivamente as possibilidades de interação (AZEVEDO, 2000).

Dentre as TICs adotadas pelas instituições que ofertam cursos na modalidade a distância via web, há o Ambiente Virtual de Aprendizagem - AVA. Este se destina a dar suporte às atividades de ensino e aprendizagem mediadas por TICs, uma vez que permite integrar diferentes mídias, linguagens e recursos, apresentar informações de maneira organizada e desenvolver interações entre pessoas e objetos do conhecimento. (ALMEIDA, 2001). Embora o AVA apresente muitas possibilidades de interação e compartilhamento e criação de conhecimento, outras ferramentas de comunicação e interação estão disponíveis na internet e são utilizadas por agentes de um curso de EaD. Essas "outras ferramentas" muitas vezes não são institucionalizadas no curso, não são incentivadas e o seu uso e potencialidades nem sempre são de conhecimento dos integrantes do curso. 


\section{COMPARTILHAMENTO DE CONHECIMENTO: OS MEIOS UTILIZADOS NO CONTEXTO DA EDUCAÇÃO A DISTÂNCIA \\ DOI: http://dx.doi.org/10.5007/1983-4535.2015v8n1p68}

Com base nisso, elaborou-se o quadro 2 com as ferramentas elencadas pelos autores Mattar (2012), Dias e Leite (2010), Romani e Rocha (2001); Santos e Rodrigues (1999). Ressalta-se ainda que essas ferramentas de comunicação figuram entre as 20 mais utilizadas pelos profissionais de educação segundo pesquisa realizada em 2011 pelo Centre for Learning and Performance Technologies. Em tempo, destaca-se que o e-mail, segundo a ABRAED (2008), é o recurso mais utilizado pelos cursos de EaD no Brasil, com 77,9\% das instituições de ensino o utilizando como recurso tutorial.

\begin{tabular}{|c|c|}
\hline $\begin{array}{l}\text { Ferramenta de } \\
\text { comunicação }\end{array}$ & Descrição \\
\hline Google apps & $\begin{array}{l}\text { A ferramenta possui a versão standart e a education e são formadas por um conjunto de } \\
\text { softwares (não é necessário a instalação de nenhum programa específico) que tem por intuito } \\
\text { a otimização da comunicação rápida e compartilhada entre as pessoas. A versão education } \\
\text { oferece, para alunos e professores, os seguintes aplicativos e serviços: Google Docs, Google } \\
\text { Sites, APIs (Application Programming Interfaces) Gmail, Google Talk, Google Calendar, } \\
\text { Galeria de soluções. }\end{array}$ \\
\hline $\begin{array}{c}\text { Correio } \\
\text { eletrônico (e- } \\
\text { mail) }\end{array}$ & $\begin{array}{l}\text { Inicialmente foi desenvolvido para a troca de mensagens textuais, no entanto, sua aplicação } \\
\text { vai além disso, de forma geral de um modo geral, engloba todos que estão envolvidos com o } \\
\text { curso, fazendo questionamentos, comentários ou sugestões (ROMANI; ROCHA, 2001). As } \\
\text { principais vantagens são: a transmissão de mensagens é rápida (virtualmente instantânea); } \\
\text { uma mesma mensagem pode ser enviada para vários destinatários simultaneamente; uma } \\
\text { mensagem pode conter som e imagens. O e-mail destaca-se de outras mídias, segundo } \\
\text { Santos e Rodrigues (1999), em virtude de é o serviço mais utilizado da Internet; é comum } \\
\text { encontrar na EaD que implementam um correio eletrônico interno de uso exclusivo no } \\
\text { âmbito do sistema; é fácil de usar; é amplamente disponível a qualquer usuário da Internet; } \\
\text { por ser uma forma de comunicação assíncrona permite que as mensagens recebidas sejam } \\
\text { analisadas com cuidado antes de serem respondidas. }\end{array}$ \\
\hline $\begin{array}{c}\text { Grupos de } \\
\text { discussão/lista } \\
\text { de discussão }\end{array}$ & $\begin{array}{l}\text { O fato de o e-mail permitir o envio de uma mensagem para vários destinatários permitiu que } \\
\text { grupos de usuários o utilizassem como meio de discussão de um tema de interesse comum. } \\
\text { Existem grupos fechados com um moderador (que permite ou não a inclusão de novos } \\
\text { usuários na discussão) e grupos abertos onde qualquer usuário da rede pode fazer parte. } \\
\text { Toda mensagem deve ser enviada para o endereço do grupo, para que todos os integrantes } \\
\text { tenham acesso ao conteúdo. }\end{array}$ \\
\hline $\begin{array}{c}\text { Conversação/ } \\
\text { Chat }\end{array}$ & $\begin{array}{l}\text { O chat é um canal de comunicação que permite a comunicação online. A principal } \\
\text { característica do chat é permitir a comunicação em grupo de forma livre e espontânea. Faz- } \\
\text { se necessário que tenha um agendamento previamente estabelecido para que os participantes } \\
\text { estejam conectados ao mesmo tempo. É uma boa forma para exposição de ideias e } \\
\text { esclarecimento de dúvidas entre alunos e professores, no entanto não é aconselhável para o } \\
\text { aprofundamento dos temas uma vez que ocorrem em tempo real. No entanto questões } \\
\text { levantadas no chat podem ser aprofundadas em outros momentos com outras ferramentas, } \\
\text { como o fórum. }\end{array}$ \\
\hline Fórum & $\begin{array}{l}\text { O fórum enquanto ferramenta tecnológica, favorece a interação e propicia a exposição de } \\
\text { diferentes pontos de vista a respeito de um tema especifico. No contexto EaD, favorece a } \\
\text { aprendizagem colaborativa e apresenta grandes possibilidades de interação. Ocorre } \\
\text { assincronamente e deve ter um acompanhamento dos professores a fim de gerenciar e } \\
\text { organizar os pontos já citados. }\end{array}$ \\
\hline Blog & $\begin{array}{l}\text { O blog surgiu em } 1999 \text { com a utilização do software norte americano Blogger, cujo objetivo } \\
\text { era facilitar a publicação de textos online sem a necessidade de ter conhecimentos } \\
\text { específicos em computação. A facilidade para editar e atualizar contribui para difusão da } \\
\text { ferramenta e o blog pode ser pessoal ou coletivo, o seu uso pode ser para a publicação de } \\
\text { textos e trabalhos produzidos individualmente ou e conjunto, para fornecer informações, }\end{array}$ \\
\hline
\end{tabular}




\section{COMPARTILHAMENTO DE CONHECIMENTO: OS MEIOS UTILIZADOS NO CONTEXTO DA \\ EDUCAÇÃO A DISTÂNCIA \\ DOI: http://dx.doi.org/10.5007/1983-4535.2015v8n1p68}

propor questões e links para outros sites. Além disso, permite a inclusão de comentários. Quando bem utilizados, contribuem significativamente para a produção coletiva de conhecimentos. Os serviços mais populares para a utilização de um blog são o Worpress e Blogger, além disso, o Moodle possui esse recurso.

É uma rede social filiada ao Google e criada em 2004 onde é possível relacionar-se com

Orkut pessoas e comunidades com as quais se tem afinidade e ter uma pagina personalizada com fotos e dados pessoais. Normalmente as amizades da rede social normalmente começaram fora da internet.

É um software colaborativo que permite a edição coletiva de documentos ou seja, a produção de textos de forma colaborativa. O que diferencia a wiki de um texto comum, é que na wiki diversas pessoas podem editar o texto.

O Facebook é uma rede social onde cada membro tem o seu perfil e a pagina inicial é personalizada para cada membro, mostrando feeds de noticias em função de suas

Facebook preferencias previamente determinadas. Entre os usuários pode ocorrer o compartilhamento de fotos, arquivos, links e comentários. Há a possibilidade de grupos abertos e fechados, eventos e de páginas (normalmente institucionais).

$\mathrm{O}$ Youtube permite que os usuários carreguem e assistam a vídeos em formato digital nas

Youtube mais variadas categorias. A facilidade de localização, produção e distribuição de vídeos fez com que o canal se popularizasse e fosse utilizado também para fins educacionais. Faculdades e Universidades costumam criar canais no site para disponibilizar seus vídeos. Através de ferramentas instantâneas de voz e vídeo como o Skype e o MSN é possível comunicar-se gratuitamente com pessoas de todo o mundo. O Skype oferece ainda um serviço direcionado para os professores, onde auxilia os professores a utilizarem a ferramenta para ajudar na aprendizagem e para compartilharem experiências e conhecimentos.

Quadro 02 Ferramentas de comunicação viabilizadas pela internet.

Fonte: Mattar (2012); Dias e Leite (2010); Romani e Rocha (2001); Santos e Rodrigues (1999).

Percebe-se que algumas das ferramentas de comunicação, como o blog, vídeos no youtube, redes sociais e e-mail também são consideradas formas de compartilhar conhecimento conforme os autores citados na sessão anterior.

\section{PROCEDIMENTOS METODOLÓGICOS}

Este trabalho caracteriza-se como uma pesquisa qualitativa descritiva, uma vez que objetiva em primazia a descrição de determinada população ou fenômeno ou ainda o estabelecimento entre as variáveis (GIL, 1991). O método utilizado para a realização da pesquisa foi o estudo de caso, este teve como objeto de estudo o ambiente Curso de Graduação em Administração à Distância oferecido pelo Departamento de Ciências da Administração da Universidade Federal de Santa Catarina.

O meio para coleta de dados utilizados nessa pesquisa foi a entrevista semi estruturada. Estas foram realizadas presencialmente nos polos de ensino a Distância UAB do estado de Santa Catarina (Lages, Tubarão, Laguna, Criciúma, Araranguá, Palhoça, 
Florianópolis, Joinville, Canoinhas, Chapecó) e na sala de tutoria do curso na UFSC entre os meses de fevereiro e setembro de 2012.

Os participantes desse estudo ocupavam seis diferentes funções: tutores presenciais; tutores a distância, coordenadores de polo; alunos; supervisor de tutoria e o responsável técnico do AVA do curso. A escolha dos informantes deu-se de forma intencional. O quadro 03 sintetiza o número de participantes em cada função.

Em tempo, é importante apontar que os alunos participantes dessa pesquisa estavam no final do curso, alguns no último e outros no penúltimo semestre. O tutor a distância trabalha há aproximadamente 5 anos na função. Com relação aos coordenadores, predominantemente eles ocupam esse cargo desde a fundação do polo de apoio presencial. A respeito dos tutores presenciais, havia duas situações, em uma o tutor presencial estava desde o início do curso acompanhando a turma e em uma situação menos comum, o tutor havia assumido a turma a menos de dois semestres. O responsável técnico ocupa o cargo há aproximadamente 5 anos e o supervisor de tutoria há 18 meses sendo que antes de ser supervisor ocupou a função de tutor.

\begin{tabular}{|lc|}
\multicolumn{1}{|c|}{ Função } & Número de entrevistados \\
\hline Tutor presencial & 8 \\
\hline Tutor a distância & 1 \\
\hline Coordenador de polo & 9 \\
\hline Responsável técnico & 1 \\
\hline Supervisor de tutoria & 1 \\
\hline Aluno & 9 \\
\hline Total & 29 participantes \\
\hline
\end{tabular}

Quadro 03 Participantes da pesquisa.

Fonte: dados primários.

As entrevistas foram gravadas e posteriormente transcritas. A análise dos dados foi realizada de acordo com o paradigma interpretativista.

\section{ANÁLISE}

Os participantes da pesquisa são agentes do curso de graduação em Administração na modalidade a distância da Universidade Federal de Santa Catarina. O curso teve sua primeira turma com início em 2006 e faz parte do Sistema Universidade Aberta do Brasil. O curso adota como ambiente virtual de aprendizagem a plataforma Moodle. A comunicação entre alunos e tutores a distância pode se dá predominantemente por meio do ambiente virtual de ensino-aprendizagem, por e-mail ou por telefone, enquanto com o tutor presencial pode ser 
também no polo. Com relação às atividades presencias, têm-se, além das provas e os seminários temáticos. As provas e seminários constituem-se com atividades obrigatórias. A proposta do seminário temático é de aprofundar o conteúdo e promover a relação teoria e prática.

Com relação aos meios pelos quais os integrantes do curso compartilham conhecimento, foi identificado, através da análise das entrevistas, que as formas utilizadas para compartilhar conhecimento no curso podem ser classificados em dois grandes grupos: os meios que fazem uso das TICs e os meios que não fazem uso das TICs. O quadro 04 apresenta quais são esses meios e a sua classificação.

\begin{tabular}{|l|l|}
\hline \multicolumn{1}{|c|}{ Meios que fazem uso das TICs } & \multicolumn{1}{c|}{ Meios que não fazem uso das TICs } \\
\hline E-mail & Encontros presencias - Seminários \\
\hline Blog/Site & $\begin{array}{l}\text { Encontros presenciais formais de tutores } \\
\text { e coordenadores }\end{array}$ \\
\cline { 1 - 2 } MSN/Gtalk & \multirow{2}{*}{ Grupo de Estudo } \\
\cline { 1 - 2 } Telefone/Skype & \\
\cline { 1 - 2 } Redes Sociais &
\end{tabular}

Quadro 04 Meios para o compartilhamento de conhecimento.

Fonte: Dados Primários.

Com base nos meios apresentados no quadro 04, passa-se a análise do uso de cada um dos meios. Inicia-se por aqueles que não fazem uso de TICs.

Dentre os meios de compartilhamento de conhecimento que não fazem uso de TICs, há os encontros presenciais formais, ou seja, aqueles que foram definidos previamente pela coordenação, como os seminários temáticos e os treinamentos e encontros dos tutores e coordenadores, já os encontros presenciais informais caracterizam-se pela auto-organização dos alunos e por vezes por incentivo dos tutores.

Os Seminários aconteciam como atividade obrigatória e avaliativa aos finais de semestre onde trabalhos desenvolvidos por grupos de alunos eram apresentados a professores e tutores no polo de apoio presencial. Estes seminários foram considerados pelos alunos momentos intensos de aprendizagem tanto no nível individual como de grupo, o aluno 1 destaca que era um momento de troca de experiências e conhecimentos além de uma oportunidade de conhecer melhor os colegas: "O que nós construímos de conhecimento foi através de seminários, que foi algo muito positivo, muito bom, porque nós conseguimos através dos seminários colocar um pouco de prática em tanta teoria (...).”

Um do alunos (8), aponta o fato da necessidade de preparação prévia dos seminários, fato que levava a prévios entre os integrantes do grupo para planejar, preparar e estudar o 
seminário antes das apresentações. Ou seja, o seminário além de ser um momento de compartilhamento por si só, ainda gerava outros momentos de compartilhamento entre os alunos no que se refere a sua preparação. Além disso, era recorrente pequenas confraternizações após as apresentações, onde em um momento de descontração os alunos, professores e tutores também trocavam ideias e experiências, além de estabelecer vínculos. Diante disso, consideram-se os seminários temáticos como momentos que oportunizaram muitas trocas e aprendizados principalmente entre os alunos, sendo fundamentais para o compartilhamento de conhecimento do curso.

O Grupo de Estudo é caracterizado pela sua não obrigatoriedade e pela informalidade com que aconteciam e destacam-se por terem sido muito utilizada pelos alunos para estudarem juntos e superarem as dificuldades de aprendizagem em grupo. Os encontros aconteciam tanto no polo de apoio presencial quanto na residência dos alunos. A motivação para a formação dos grupos foi a necessidade de realizar trabalhos em grupo e também a dificuldade maior percebida pelos alunos em disciplinas que envolviam matemática, como estatística e contabilidade. A formação destes, deu-se forma natural no início do curso, os alunos agruparam-se com base nas afinidades e na empatia. Com relação aos grupos, o coordenador de polo 08 opina afirmando que os grupos são fundamentais para o bom desempenho dos alunos, e que aqueles que fizeram parte de grupos dessa natureza foram os primeiros a finalizar o curso.

Ainda no âmbito de encontros presenciais, houve os Encontros Presenciais Formais de Tutores e Coordenadores de Polo. Esses encontros consistiam em capacitações, treinamentos e seminários organizados pela UAB (ou pelos coordenadores de cada curso. Tutores presenciais e coordenadores de polo afirmaram que estes momentos eram fundamentais para conhecer a equipe da UFSC, os outros tutores e outros coordenadores, além de ser um momento de trocas de experiência e compartilhamento de conhecimento. Os tutores presenciais 2 e 3 manifestaram-se a respeito com os seguintes depoimentos: "Esses momentos que a gente teve em Florianópolis para cursos com esses tutores, é muito legal, porque é uma troca de experiência legal, porque daí cada um falando do seu polo, da sua realidade é bem enriquecedor essa parte que teve" (Tutor Presencial 3). "Quando houveram as capacitações, que eu acho muito importante, é um momento de interação com a UFSC, como o coordenador, com o nosso tutor a distância, a gente sentia essa necessidade (...)" (Tutor Presencial 2). 


\section{COMPARTILHAMENTO DE CONHECIMENTO: OS MEIOS UTILIZADOS NO CONTEXTO DA \\ EDUCAÇÃO A DISTÂNCIA \\ DOI: http://dx.doi.org/10.5007/1983-4535.2015v8n1p68}

É possível perceber a relevância dos momentos presenciais para os agentes do curso. Nesse sentido os autores Davenport e Prusak (1998) defendem o compartilhamento de conhecimento através das interações face a face uma vez que os sinais que confiança e convencimento são melhor transmitidos na comunicação pessoal. Segundo a APO (2009), os referidos encontros presenciais fazem parte da forma de compartilhamento denominada "fluxo" uma vez que nestes encontros há a transferência direta de conhecimento entre as pessoas.

Especificamente com relação aos seminários temáticos e aos encontros presenciais formais de tutores e coordenadores, estes também são considerados formas de compartilhamento de conhecimento segundo CEN (2010). Com relação às técnicas e métodos apontados por Young (2010), os grupos de estudos tanto para as disciplinas quanto para a elaboração de trabalhos podem ser consideradas como a técnica Assistência entre Colegas uma vez o conhecimento de um colega auxiliou na resolução de uma questão importante naquele momento e assim, encurtou a curva de aprendizagem do grupo. Ainda é possível afirmar que, na maioria das vezes, o polo de apoio presencial foi um espaço propicio ao compartilhamento de conhecimento como preconizado por Lee e Yang (2000).

Apresentados os resultados dos meios presenciais, passa-se a analise dos meios que fazem uso de tecnologias da informação.

O E-mail certamente foi o meio mais citado pelos participantes, todos os participantes citaram o uso do e-mail para a interação com os demais envolvidos e muitos indicaram que esse é o principal meio utilizado para comunicação: "hoje a nossa prática maior é por e-mail" (Coordenador de Polo 7); "É por e-mail, tudo por e-mail” (Supervisor de Tutoria); “a maior parte das dúvidas e dos contatos eu fiz através do e-mail" (Aluno 3); "a principal forma é online, é e-mail" (Coordenador de Polo 6); "A minha colega que a gente fez o trabalho juntas a gente sempre fez pelo ambiente, não pelo AVA, mas por e-mail" (Aluno 8); O tutor a distância 1 ainda observa que quando o aluno tinha vergonha de perguntar durante um chat ou videoconferência, ele recorria ao e-mail e se explicava que por e-mail se sentia mais a vontade para perguntar. Nesse sentido a ABRAED (2008) afirma que o e-mail é o recurso mais utilizado nos cursos de EaD no Brasil.

Com relação as motivações para utilizar o e-mail com essa frequência, percebeu-se que a familiaridade de uso do e-mail, a rapidez e o incentivo da coordenação no início do curso foram motivos citados pelos participantes como pode-se perceber na fala do aluno 2: "a 


\section{COMPARTILHAMENTO DE CONHECIMENTO: OS MEIOS UTILIZADOS NO CONTEXTO DA \\ EDUCAÇÃO A DISTÂNCIA \\ DOI: http://dx.doi.org/10.5007/1983-4535.2015v8n1p68}

gente acaba utilizando outras tecnologias e-mail, msn, que acaba sendo muito mais rápido”. A proliferação do uso pode ser entendida também pelas vantagens que a ferramenta utiliza, como apontado pelos teóricos de $\mathrm{EaD}$ : transmissão de mensagens é rápida (virtualmente instantânea); uma mesma mensagem pode ser enviada para vários destinatários simultaneamente; é o serviço mais utilizado da Internet; é fácil de usar; é amplamente disponível a qualquer usuário da Internet; por ser uma forma de comunicação assíncrona (MATTAR, 2012; DIAS; LEITE, 2010; ROMANI; ROCHA, 2001; SANTOS; RODRIGUES, 1999) percebe-se que os motivos que levam ao uso identificados nas entrevistas vão de encontro ao que a literatura aponta como vantagens da ferramenta.

O uso do MSN também é citado pela maioria dos alunos, tutores, coordenadores e responsável técnico. De acordo com o tutor presencial 6 "Todo mundo tem o msn de todo mundo, eles (alunos) trocam ideias. As vezes eu estou conversando no msn com uns dois alunos, com duas conversas ao mesmo tempo do mesmo grupo" e o aluno 7 declara : "a gente passa a tarde inteira no me-mailsn conversando com os colegas, então o nosso contato é assim mesmo". O Skype por sua vez, foi citado por alguns alunos, principalmente aqueles que estavam envolvidos na comissão de formatura, "eu participo da comissão de formatura e aí estamos tendo mais contato com outros polos através do Skype. Acho que é uma ferramenta que nós podemos usar bastante agora" (Aluno 8). Percebeu-se que o MSN e o Skype são muito utilizados pelos alunos, mas com menor intensidade do que o e-mail e a finalidade de uso é para conversar com os colegas e com os tutores, mas não necessariamente assuntos relativos ao conteúdo, conversas de apoio e motivação foram relatadas pelos participantes como conteúdo das conversas pelos referidos meios:

A gente faz muito aquele socialzinho sabe, aquele namoro, de trocar ideia aqui, conversar ali...o aluno diz - ah eu estou com um problema assim, acho que vou desistir. Aí você fica naquela colocando gás, colocando pilha, incentivando. Faz parte e geralmente é isso que a gente mais faz, esse estímulo (Tutor presencial 2).

O Skype e o MSN são ferramentas de comunicação viabilizadas pela internet apontadas pelos teóricos de EaD Mattar (2012) e Dias e Leite (2010) e além disso figuram entre as mais utilizadas na educação segundo o Centre for Learning and Performance Technologies em 2011.

O uso das Redes Sociais observou-se a predominância do Orkut no início do curso principalmente para o compartilhamento de fotos da turma e dos eventos (aula inaugural, 


\section{COMPARTILHAMENTO DE CONHECIMENTO: OS MEIOS UTILIZADOS NO CONTEXTO DA \\ EDUCAÇÃO A DISTÂNCIA \\ DOI: http://dx.doi.org/10.5007/1983-4535.2015v8n1p68}

encontro em Florianópolis, entre outro) e havia também uma comunidade onde, segundo o tutor a distância 1 "eu já vi uma comunidade no antigo Orkut, onde os alunos tinham feito para trocar informações, e até tinha coisas ali, também de atividades que eles ficavam com receio de conversar no Moodle e achavam que no Orkut eles poderiam conversar melhor sobre aquilo." Pela fala do tutor presencial percebe-se que nesses ambientes informais eles sentiam-se mais a vontade para compartilhar determinadas percepções e opiniões.

O Facebook, por sua vez foi apontado como a rede social atualmente utilizada, como pode-se observar pela fala dos alunos 2 e 3: "Eu tenho Facebook, sou moderno" (Aluno 3), "Eu tenho Face, Orkut nem mexo mais" (Aluno 2). O contato entre os alunos no Facebook era esporádico, segundo o aluno 3, eram trocas rápidas de apoio via comentários nas postagens dos colegas ou troca de informações rápidas. Segundo o coordenador de polo 8, o Facebook é uma ferramenta de comunicação eficiente para comunicações rápidas: "Eu sempre digo que o Facebook para esse tipo de coisa funciona que é uma maravilha, se tu dá um recado rápido o aluno está sempre conectado." Nesse sentido, o tutor presencial 7 complementa afirma que os alunos usam o Facebook, e o que a gente observa é que todos tem e as vezes eles fazem algum comentário "ah amanhã tem a prova", " a prova foi fácil, a foi difícil”. Coisas assim, mas mais superficiais. Eu acho que o aprofundamento é mais por e-mail mesmo e pessoalmente quando se encontram.

Em uma das entrevistas, o aluno 8 citou a existência de uma página no Facebook do Polo, então a partir dessa informação, localizou-se no Facebook esta página e analisou-se o tipo de informação que existia ali. A página é aberta ao público e constatou-se que esta é utilizada para divulgação do Polo, nesta encontrou-se a divulgação de atividades realizadas no polo principalmente por fotos, a postagem de notícias referentes ao polo e compartilhamento de vídeos e reportagens relacionadas aos cursos que aquele espaço abriga. Dentre os 10 polos entrevistados e visitados, essa iniciativa foi única. As Redes Sociais também são citadas pelos teóricos de EaD Mattar (2012) e Dias e Leite (2010) e também figuram entre as mais utilizadas na educação segundo o Centre for Learning and Performance Technologies em 2011.

O uso de blogs e sites também foi identificado entre os participantes. Com relação ao blog, identificou-se o uso em três ocasiões, sendo que em uma delas, o êxito foi evidenciado pelos alunos. A primeira iniciativa foi em um polo logo que este foi inaugurado, o tutor presencial 1 relatou essa iniciativa durante a entrevista e a partir dessa informação, buscou-se 


\section{COMPARTILHAMENTO DE CONHECIMENTO: OS MEIOS UTILIZADOS NO CONTEXTO DA \\ EDUCAÇÃO A DISTÂNCIA \\ DOI: http://dx.doi.org/10.5007/1983-4535.2015v8n1p68}

o blog na Internet (http://eadpolodelages.zip.net/) e observou-se que a última postagem era de 2007, entendeu-se dessa forma, que o blog não é mais utilizado pelo polo. Observou-se que neste eram compartilhadas fotos e notícias sucintas dos eventos que aconteciam no polo. A segunda iniciativa foi descrita pelo responsável técnico: "Eu sei que muitos chegaram a criar blogs fora do ambiente virtual (...), alguns blogs até meio que na verdade seriam para... postar atividades, compartilhar atividades prontas." Este blog não foi localizado na rede. E a terceira aplicação para o blog foi realizada pela comissão de formatura para compartilhar as decisões que iam sendo tomadas e o que precisava ser providenciado com todos os alunos (http://ufscadm-pp2.blogspot.com.br/), segundo o aluno 3 "está funcionando como um instrumento de comunicação." Este blog foi localizado na internet e pode-se verificar que era bem estruturado e continha informações referentes as solenidades de formatura, resultados de eleições para escolha de professores homenageados, patrono e paraninfo e também informações que poderiam ajudar os alunos que não eram de Florianópolis (as solenidades de formatura aconteceram na referida cidade) como lista com números úteis, mapas com a localização da rodoviária e da UFSC e sugestões de salões de beleza para as formandas.

No blog, onde há a possibilidade dos visitantes comentarem os conteúdos postados, não foi localizado nenhum comentário dos colegas embora o blog fosse atualizado constantemente. Segundo os teóricos de EaD Mattar (2012) e Dias e Leite (2010), os blogs quando bem utilizados, contribuem significativamente para a produção coletiva de conhecimentos, em tempo ressalta-se que os blogs também estão entre os recursos mais utilizados por profissionais da educação de acordo o Centre for Learning and Performance Technologies.

Com relação ao uso de site, identificou-se uma iniciativa nesse sentido com o coordenador de polo 8 que revelou durante a entrevista que o polo possuía um site (http://www.polocanoinhas.hd1.com.br/ ), com base nessa informação, buscou-se localizar o site e verificou-se que o site contem uma parte dedicada apenas as informações os cursos que são oferecidos no mesmo e a opção de redirecionamento para as páginas oficiais dos cursos nos sites oficiais das instituições de ensino. Além disso, há informações sobre o polo, sua equipe e funcionamento e uma área dedicada às notícias. São disponibilizados ainda fotos de eventos realizados no polo e das formaturas que já aconteceram. Constatou-se a atualização semanal do site. 


\section{COMPARTILHAMENTO DE CONHECIMENTO: OS MEIOS UTILIZADOS NO CONTEXTO DA \\ EDUCAÇÃO A DISTÂNCIA \\ DOI: http://dx.doi.org/10.5007/1983-4535.2015v8n1p68}

Diante do exposto verificamos que os agentes do curso utilizaram diferentes meios para compartilhar conhecimento e que este processo aconteceu tanto de forma espontânea como estruturada.

\section{CONSIDERAÇÕES FINAIS}

O compartilhamento de conhecimento por meio das interações aconteceu por diferentes meios, alguns suportados pelas TICs e outros de forma presencial. As formas suportadas pelas TICs identificadas são: o e-mail como o mais utilizado por todos os participantes; o Blog como uma iniciativa da comissão de formatura para organização e disseminação das informações referentes ao evento; Sites dos polos com a finalidade de divulgação do mesmo para a comunidade; Redes Sociais, especificamente o Orkut e o Facebook para interações mais superficiais entre os envolvidos; o MSN e o Skype são muito utilizados pelos alunos e tutores mas em menor frequência comparado ao e-mail, destaca-se que o seu uso ia além das questões relacionadas ao conteúdo e abarcava conversas de apoio e motivação; o Telefone também emergiu mas sempre associado ao e-mail, normalmente era usado em situações urgentes.

Quanto aos meios presenciais, Davenport e Prusak (1998) defendem as interações face a face alegando que sinais de confiança e convencimento são melhores transmitidos na comunicação pessoal. Nesse contexto três situações destacaram-se: os seminários temáticos, os encontros formais de tutores e coordenadores e os grupos de estudo. Os seminários temáticos eram atividades obrigatórias ao final dos semestres onde grupos de alunos deveriam apresentar um seminário sobre um tema previamente determinado, essa atividade oportunizou trocas e aprendizados intensos principalmente entre os alunos não apenas no momento em que o seminário acontecia, mas também na sua preparação pelos grupos.

Os encontros formais de tutores e coordenadores consistiam em capacitações, treinamentos e seminários organizados pela $\mathrm{UAB}$ ou pelos coordenadores de cada curso, esses encontros caracterizaram-se como fundamentais para que coordenadores de polo e tutores presenciais conhecessem a equipe da UFSC e compartilhassem experiências e conhecimentos com os seus pares. Os grupos de estudo, por sua vez, são marcados pela informalidade e não obrigatoriedade, eram organizados pelos próprios alunos ou pelos tutores presenciais, aconteciam no polo, na própria casa dos alunos ou em bibliotecas e eram realizados para que os alunos estudassem juntos e se auxiliassem mutuamente. 


\section{COMPARTILHAMENTO DE CONHECIMENTO: OS MEIOS UTILIZADOS NO CONTEXTO DA \\ EDUCAÇÃO A DISTÂNCIA \\ DOI: http://dx.doi.org/10.5007/1983-4535.2015v8n1p68}

A modalidade a distância, pela sua natureza, oferece menos oportunidades para as pessoas se envolverem em situações presenciais (NA UBON; KIMBLE, 2002) e isso tem reflexos no compartilhamento de conhecimento. No entanto, observou-se que no curso estudado os envolvidos utilizaram recursos tecnológicos além do que estava previsto pela coordenação do curso, como o Skype, as redes sociais, os sites e blogs, e se organizaram em novos arranjos, como os grupos de estudos. Os recursos e arranjos não previstos combinados com os meios planejados (e-mail, seminários temáticos, treinamentos e capacitações) permitiram o compartilhamento de conhecimento entre os agentes do curso.

\section{REFERÊNCIAS}

ABRAEAD - Anuário Brasileiro Estatístico de Educação Aberta e a Distância. 4.ed. São Paulo: Instituto Monitor, 2008.

ALMEIDA, Maria Elizabeth Bianconcini de. Formando professores para atuar em ambientes virtuais de aprendizagem. In: ALMEIDA, F. J. (Coord). Projeto Nave. Educação a distância: formação de professores em ambientes virtuais e colaborativos de aprendizagem. São Paulo: [s.n.], 2001.

ALMEIDA, Maria Elizabeth Bianconcini de. Educação a distância na Internet: abordagens e contribuições dos ambientes digitais de aprendizagem. Educ. Pesqui. [on line]. v. 29, n. 2, p. 327-340, 2003.

APO. Asian Productivity Organization. Knowledge Management: Facilitators Guide. Tokyo, 2009.

AZEVEDO, W. Panorama atual da Educação a distância no Brasil. 2000. Disponível em: $<$ http://www.revistaconecta.com/conectados/wilson_seminario.htm>. Acesso em: 10 nov. 2012.

BELLONI, Maria Luiza. Educação a distância. 5 ed. Campinas: Autores Associados, 2009.

CEN. European Guide to Good Practice in Knowledge Management. Part 1: Knowledge Management Framework: European Committee for Standardization, 2004.

CHRISTENSEN, P. H. Knowledge sharing: moving away from the obsession with best practices. The Journal of Knowledge Management, v.11, p. 36-47, 2007.

DAVENPORT, T. H.; PRUSAK, L. Conhecimento Empresarial: como as organizações gerenciam o seu capital intelectual. Rio de Janeiro: Campus, 1998.

DIAS, R. A., LEITE, L. S. Educação a Distância: da legislação ao pedagógico. Petrópolis: Vozes, 2010. 
GIL, Antonio Carlos. Como elaborar projetos de pesquisa. 3. Ed. São Paulo: Atlas, 1991.

HENDRIKS, P. Why share knowledge? The influence of ICT on motivation for knowledge sharing. In: Knowledge and Process Management, v. 2, n.6, p. 91-100, 1999.

HONG, D.; SUH, E.; KOO, C. Developing strategies for overcoming barriers to knowledge sharing based on conversational knowledge management: A case study of a financial company. Expert Systems with Applications, n.38, 2011.

LEE, C. .C, Y,JIE, Knowledge value chain, Journal of Management Development, Vol. 19 Iss: 9 , pp. $783-794,2000$

MATTAR, J. Tutoria e interação em educação a distância. São Paulo: Cengage Learning, 2012.

MOORE, Michael; KEARSLEY, Greg. Educação a distância: uma visão integrada. São Paulo: Thomson, 2007.

NA UBON, A.; KIMBLE, C. Knowledge Management in Online Distance Education. Proceedings of the 3rd International Conference Networked Learning, University of Sheffield, UK. p.465-473, 2012.

NAHAPIET, J.; GHOSHAL, S. Social Capital, Intellectual Capital, and the Organization Advantage. Academy of Management Review, v. 23, n. 2, p.242-266, 1998.

SANTOS, F. F. Modelo de gestão para promover a criação e o compartilhamento de conhecimento em comunidade virtual de prática. 2010, $242 \mathrm{f}$. Tese (Doutorado em Engenharia e Gestão do Conhecimento) - Universidade Federal de Santa Catarina, Florianópolis, 2010.

SOARES, Aline Pereira. Gestão do Conhecimento e conflitos interorganizacionais em EaD: construção de uma teoria substantiva. 2012. Tese (Doutorado em Engenharia e Gestão do Conhecimento) - Programa de Pós graduação em Engenharia e Gestão do Conhecimento, Universidade Federal de Santa Catarina, Florianópolis, 2012. Disponível em:

http://btd.egc.ufsc.br/wp-content/uploads/2012/10/ALINE-PEREIRA-SOARES-tese-finalD1.pdf. Acesso em: 04 out. 2012.

ROMANI, Luciana Alvin Santos; ROCHA, Heloisa Vieira. A complexa tarefa de educar a distância: uma reflexão sobre o processo educacional baseado na web. Revista Brasileira de Informática na Educação, n.8, p.71-81, 2001. Florianópolis: Comissão especial de informática da Sociedade Brasileira de Computação, 2001.

YOUNG, Ronald, Knowledge Management Tools and Techniques Manual. Published by the Asian Productivity Organization, Tokyo, 2010. 